\title{
Patterning the Dorsal Telencephalon: A Role for Sonic Hedgehog?
}

\author{
Brian G. Rash and Elizabeth A. Grove \\ Department of Neurobiology, Committees on Neurobiology and Developmental Biology, University of Chicago, Chicago, Illinois 60637
}

Division of the telencephalic vesicle into hemispheres and specification of the cerebral cortex are key stages in forebrain development. We investigate the interplay in these processes of Sonic hedgehog (Shh), fibroblast growth factors (Fgfs), and the transcription factor Gli3, which in its repressor form (Gli3R) antagonizes Shh signaling and downregulates expression of several Fgfgenes.

Contrary to previous reports, Shh is not required for dorsal hemisphere separation. Mice lacking Shh develop a dorsal telencephalic midline, a cortical hem, and two cortical hemispheres. The hemispheres do not divide rostrally, probably because of reduced local $\mathrm{Fg}$ gene expression, resulting from the loss of Shh inhibition of Gli3R. Removing one functional copy of Gli3 substantially rescues Fgf expression and rostral telencephalic morphology.

In mice lacking Gli3 function, cortical development is arrested, and ventral gene expression invades the dorsal telencephalon. These defects are potentially explained by disinhibition of Shh activity. However, when both copies of $S h$ are removed from Gli3-null mice, dorsal telencephalic defects persist. One such defect is a large dorsal expansion of the expression of Fgf genes. Fgfl15 expression, for example, expands from a discrete ventral domain throughout the dorsal telencephalon. We propose that Fgf signaling, known to ventralize the telencephalon in a Shh-independent manner, suppresses cortical fate in the absence of Gli3. Our findings point away from Shh involvement in dorsal telencephalic patterning and encourage additional exploration of Fgf signaling and Gli3 repression in corticogenesis.

Key words: sonic hedgehog; Gli3; fibroblast growth factors; telencephalon; cerebral cortex; roofplate; cortical hem

\section{Introduction}

The mammalian telencephalon comprises the cerebral cortex and subcortical nuclei required for higher brain functions. Yet this complex structure is generated from a primitive neuroepithelium by the same molecular patterning mechanisms that operate generally in the embryo. This conceptual framework has simplified and accelerated investigation of telencephalic development (Wilson and Rubenstein, 2000; Ohkubo et al., 2002; Grove and Fukuchi-Shimogori, 2003).

Considerable evidence demonstrates that dorsoventral (D/V) patterning in the telencephalon shares mechanisms with $\mathrm{D} / \mathrm{V}$ patterning of the spinal cord. Sonic hedgehog (Shh) signaling mediated by Smoothened (Smo) promotes ventral telencephalic structure (Chiang et al., 1996; Kohtz et al., 1998; Rallu et al., 2002; Fuccillo et al., 2004), and key features of dorsal development require bone morphogenetic protein (BMP) or Wingless-Int (Wnt) signaling (Lee et al., 2000; Hebert et al., 2002, 2003; Cheng et al., 2006), as in the spinal cord (Echelard et al., 1993; Ericson et

Received Feb. 15, 2007; revised Sept. 2, 2007; accepted Sept. 7, 2007.

This work was supported by National Institute of Mental Health Grant R01 MH59962, by the Brain Research Foundation at the University of Chicago, and by a National Institutes of Health training grant administered by the Committee on Neurobiology. We thank Chip Ferguson for helpful discussions, Philip Beachy (Shh) and Yas Furuta (Gli3Xt') for mice, and Stav Assimacopoulos and Albert Taylor for experimental and technical help.

Correspondence should be addressed to Elizabeth A. Grove, Department of Neurobiology, University of Chicago, 947 East 58th Street, Chicago, IL 60637. E-mail: egrove@bsd.uchicago.edu.

D0I:10.1523/JNEUROSCI.3204-07.2007

Copyright $\odot 2007$ Society for Neuroscience 0270-6474/07/2711595-09\$15.00/0 al., 1995; Roelink et al., 1995; Liem et al., 1995, 1997; Backman et al., 2005).

Ventral telencephalic and spinal cord development is further regulated by antagonistic interactions between Shh signaling and the repressor form of Gli3 (Gli3R), a member of the Gli family of transcription factors (Litingtung and Chiang, 2000; Rallu et al., 2002). Shh inhibits the processing of Gli3 to Gli3R; thus, in Shh mutants, Gli3R is produced in excess. Illustrating the antagonism, ventral cell types are lost in both the spinal cord and telencephalon of mice deficient in Shh or Smo, but substantially rescued in compound mutants that also lack Gli3 (Litingtung and Chiang, 2000; Rallu et al., 2002). These data support a model in which a still-unidentified factor ventralizes the neural tube, is functionally inhibited by Gli3R, and is disinhibited by Shhmediated reduction of Gli3R.

Previous analyses of the telencephalon in Shh, Gli3, and compound mutant mice suggest that not all basic telencephalic patterning mechanisms are shared with other parts of the embryo. In the Shh mutant, the dorsal midline of the spinal cord is marked by formation of the roofplate; in contrast, the Shh mutant telencephalon reportedly lacks a dorsal midline and fails to divide into hemispheres (Chiang et al., 1996). How Shh induces the dorsal midline selectively in the telencephalon has been a longstanding mystery (Hayhurst and McConnell, 2003).

In mice lacking functional Gli3, no layered cortex develops, and gene expression characteristic of the ventrolateral telencephalon expands dorsally (Theil et al., 1999; Tole et al., 2000; Theil, 

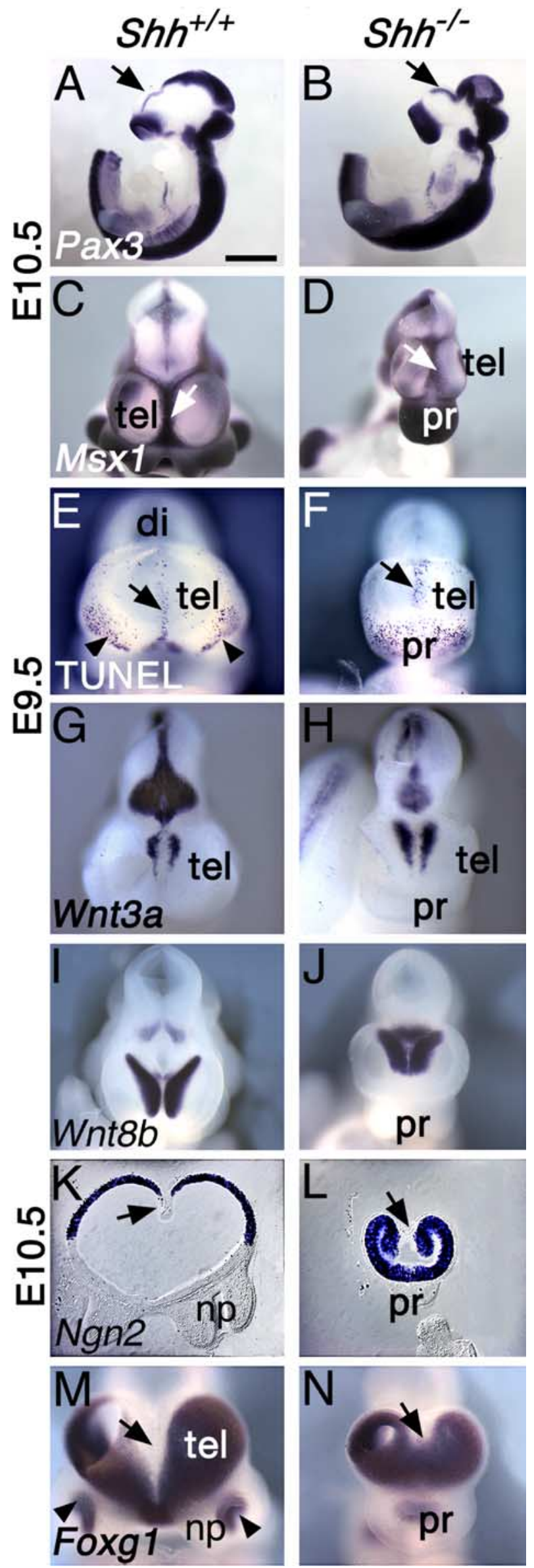

2005), suggesting that Shh signaling activity is de-repressed and inhibits dorsal telencephalic development (Tole et al., 2000; Rallu et al., 2002). Consistent with this explanation, dorsal telencephalic defects appear rescued in Gli3;Shh double mutants (Rallu et al., 2002). These observations suggest a second part to the model above: a dorsalizing factor in the telencephalon is inhibited by Shh and disinhibited by Gli3-mediated suppression of Shh signaling (Rallu et al., 2002). Notably, however, this type of interaction between Shh and Gli3 is not general; that is, defects caused by Gli3 deficiency at other embryonic sites, including the spinal cord, are not rescued by removing Shh or Smo function (Aoto et al., 2002; Litingtung et al., 2002; Persson et al., 2002).

In the present study, we investigate whether the dorsal telencephalon is patterned by specialized Shh/Gli3 activities. In doing so, we attempt to clarify the induction of the telencephalic dorsal midline, and, more broadly, specification of cerebral cortex in the dorsal telencephalon.

\section{Materials and Methods}

Mouse lines. Animal protocols were approved by the Institutional Animal Care and Use Committee of the University of Chicago, and mice were used according to National Institutes of Health guidelines. Noon of the day of vaginal plug detection was termed embryonic day 0.5 (E0.5).

Shh mutant mice (a gift from P. Beachy, Johns Hopkins University School of Medicine, Baltimore, MD) were obtained in a mixed C57BL/ $6 / 129$ background used in the initial analysis of this mutant (Chiang et al., 1996; C. Chiang, personal communication). A background strain characterization by Charles River Laboratories (Wilmington, MA) confirmed the mixed background. To decrease variability, and potentially reduce exencephaly in Shh/Gli3 compound mutants (see below), we increased the contribution of the C57BL/6 strain over five generations of additional crossbreeding. All Shh nulls from each generation showed similar gross abnormalities, including cyclopia, a facial proboscis, reduction of limb and tail bud, and loss of digits. Features of D/V forebrain development, described here, were qualitatively indistinguishable across generations. Shh ${ }^{-1-}$ embryos of a given age were therefore pooled for analysis. No Shh ${ }^{-1-}$ mice were excluded.

We found no evidence in our mice for a reduction in the deficits caused by Shh. Indeed, older Shh ${ }^{-1-}$ embryos were recovered at lower rates than previously (Chiang et al., 1996), suggesting greater earlier lethality. Between E9.5 and E12.5, however, Shh mutants were recovered at Mendelian ratios (at E10.5, $51 S h h^{+1+}, 87 S h h^{+1-}$, and $51 S h h^{-1-}$ ).

Existing evidence indicates that the extra-toes ${ }^{J}\left(X^{J}\right)$ mutation is a lossof-function mutation in the Gli transcription factor gene, Gli3 (Buscher et al., 1998). $X t^{J} / X t^{J}$ embryos can have a high incidence of midbrain exencephaly, with gross morphological changes that confound forebrain analysis. Following previous studies (Theil et al., 1999; Tole et al., 2000; Rallu et al., 2002; Kuschel et al., 2003; Theil, 2005), we restricted forebrain analysis to non-exencephalic $X t^{J} / X t^{J}$ embryos. $X t^{I}$ mice maintained on a C57BL/6 background (gift from Y. Furuta, Program in Genes and Development University of Texas, Houston, TX) show decreased exencephaly; thus, we discarded only 1 of $34 \mathrm{Xt}^{J} / \mathrm{Xt}$ E10.5 embryos.

Figure 1. Telencephalic dorsal midline development in the Shh null forms cerebral hemispheres. Whole-mount and coronal section $(\boldsymbol{K}, \boldsymbol{L})$ in situ hybridization in wild-type $\left(\mathrm{Shh}^{+/+}\right.$; left column) and Shh-null (Shh ${ }^{-1-}$; right column) embryos at E9.5 (E-H) and E10.5. Embryos are shown in lateral $(\boldsymbol{A}, \boldsymbol{B})$, dorsal $(\boldsymbol{C}, \boldsymbol{D}, \boldsymbol{G}-\boldsymbol{J})$, and frontal views $(\boldsymbol{E}, \boldsymbol{F}, \boldsymbol{M}, \boldsymbol{N}) . \boldsymbol{A}-\boldsymbol{F}$, Pax3 and MsX1 expression, and TUNEL-labeled apoptotic cells mark midline neuroepithelium $(\boldsymbol{A}, \boldsymbol{B}, \boldsymbol{E}, \boldsymbol{F}$, arrows); $M s \times 1$ is also expressed in mesenchyme invading between the hemispheres $(\boldsymbol{C}, \boldsymbol{D}$, arrows). $\mathbf{G}-\mathbf{L}$, Expression of Wnt3a and Wnt8b shows separation between two cerebral hemispheres $(\mathbf{G}-\boldsymbol{J})$, as does the lack of $N g n 2$ expression at the dorsal midline $(\boldsymbol{K}, \boldsymbol{L})$. Foxg 7 expression reveals rostral continuity of the hemispheres (compare $\boldsymbol{M}, \boldsymbol{N}$; arrows indicate interhemispheric fissure). Scale bar: $\boldsymbol{A}, \boldsymbol{B}, 1.2 \mathrm{~mm} ; \boldsymbol{C}, \boldsymbol{D}, \boldsymbol{I}, \boldsymbol{J}, 700 \mu \mathrm{m} ; \boldsymbol{E}-\boldsymbol{H}, 540 \mu \mathrm{m} ; \boldsymbol{K}-\boldsymbol{N}, 580 \mu \mathrm{m}$. Abbreviations: di, Diencephalon; tel, telencephalon; pr, proboscis; np, nasal primordia. 
Table 1. Numbers of Shh mutant mice with dorsal midline features and dorsal but not rostral hemisphere separation

\begin{tabular}{|c|c|c|c|c|}
\hline & Feature & Marker & Number of embryos & Age of embryos \\
\hline \multirow[t]{3}{*}{ Dorsal midline formation } & Roofplate & Pax3 & 3 of 3 & $\mathrm{E} 10.5$ \\
\hline & & Noggin & 3 of 3 & E10.5 \\
\hline & & Cell death & 6 of 6 & E9.5-E10.5 \\
\hline \multirow[t]{4}{*}{ Dorsal hemisphere division } & Deep interhemispheric fissure & Morphology & 18 of 18 & E12.5-E17.5 \\
\hline & Bilateral cortical hem & Wnt3a, Lmx1a, Bmp4 & 16 of 16 & E9.5-E10.5 \\
\hline & Cortical neural progenitor zones separate dorsally & Ngn2, Emx1, Emx2, Foxg1 & 15 of 15 & E10.5-E12.5 \\
\hline & Bilateral medial gene expression & Wnt8b & 3 of 3 & E10.5-E11.5 \\
\hline \multirow[t]{2}{*}{ Lack of rostral hemisphere division } & Absence of rostral interhemispheric fissure & Morphology & 18 of 18 & E12.5-E17.5 \\
\hline & Cortical neural progenitor zones fused rostrally & Ngn2, Emx1, Emx2, Foxg1 & 15 of 15 & E10.5-E12.5 \\
\hline
\end{tabular}

Mice heterozygous for both the $X t^{I}$ and Shh mutations were intercrossed to obtain $S h h ; X t^{J}$ compound mutants. At E10.5, 194 embryos were recovered. Of $43 \mathrm{Shh}^{-1-}$; Gli3/Xt mice, only 1 or 2 were exencephalic; in contrast, 12 of $16 \mathrm{Shh}^{-1-} ; X t^{J} / X t^{J}$ mutants were exencephalic. Exencephalic mutants were not analyzed further. PCR genotyping for Shh and $X t^{I}$ mice was performed as described previously (Chiang et al., 1996; Maynard et al., 2002).

In situ hybridization, tissue processing, and imaging. Embryos were fixed and processed for in situ hybridization (Grove et al., 1998). Some brains were labeled with terminal deoxynucleotidyl transferase-mediated biotinylated UTP nick end labeling (TUNEL) to identify apoptotic cells using an ApopTag kit (Chemicon, Temecula, CA) followed by an alkaline phosphatase nitroblue tetrazolium/5-bromo-4-chloro-3-indolyl phosphate color reaction. Processed tissue was imaged using a Leica (Nussloch, Germany) dissecting microscope for whole-mount embryos, and a Zeiss (Oberkochen, Germany) Axioskop for sections, and photographed using Zeiss Axiovision software.

\section{Results}

Expression of at least some genes associated with the dorsal telencephalon, Bmp2, Bmp7, Msx1, and Msx2, has been reported at increased levels in the Shh mutant telencephalon (Ohkubo et al., 2002). Here, a systematic study of the mutant telencephalon at a wide range of embryonic ages revealed an array of characteristic dorsomedial features.

\section{The dorsal midline forms and hemispheres separate in the absence of Shh}

As previously observed, the Shh mutant forebrain, like the entire CNS, is much smaller than in wild type. This reflects loss of the proliferative Shh signal, with consequent repression by Gli3R of Wnt/ $\beta$-catenin mitogenic signaling (Ishibashi and McMahon, 2002; Ulloa et al., 2007). Nonetheless, a dorsal midline is identifiable in the Shh mutant telencephalon.

By E9.5-E10.5 in control and Shh ${ }^{-1-}$ mice, the roofplate is marked by gene expression of the transcription factor Pax3, locally increased cell death, and expression of Msx genes associated with apoptosis (Fig. 1A-F; supplemental Fig. 1, available at www. jneurosci.org as supplemental material). The cerebral hemispheres separate along the dorsal midline (Fig. $1 C-N$ ), and a dorsal interhemispheric fissure persists to birth (supplemental Fig. 1, available at www.jneurosci.org as supplemental material). The Shh mutant telencephalon is therefore not an undivided holosphere as initial observations suggested (Chiang et al., 1996). Dorsal separation is unmistakable in frontal views of the Shh mutant forebrain processed for the telencephalic marker gene Foxg1 (Tao and Lai, 1992) (Fig. 1M,N). In the same views, it is also clear that the rostralmost telencephalon does not divide. The dorsal midline is further marked in mutant and control mice by the absence of $\mathrm{Ngn} 2$ expression (Fig. $1 \mathrm{~K}, \mathrm{~L}$, arrows). Features indicating formation of the dorsal midline and interhemispheric fissure, with a missing rostral fissure, were consistent across all Shh mutants assessed (Table 1).

\section{Dorsomedial structures appear on both sides of the midline}

The roofplate, defined as a band of tissue along the midline of the telencephalic vesicle, is required for development of the cortical hem (Chizhikov and Millen, 2005; Cheng et al., 2006), a second telencephalic signaling center at the dorsomedial edge of each hemisphere (Furuta et al., 1997; Grove et al., 1998). Between E9.5 and E10.5, expression of Wnt3a, Bmp4, and Lmxla indicates that a hem has formed in both hemispheres in Shh mutants as in controls (Fig. 1G,H; supplemental Fig. 1, available at www. jneurosci.org as supplemental material). By E10.5, Wnt $3 a$ and $8 b$ expression patterns give the impression that the hem in each hemisphere has fused across the caudal midline (Figs. $1 \mathrm{I}, \mathrm{J}$, $4 A, E)$. These patterns reflect, instead, an upregulation of Wnt gene expression in the diencephalon (B. G. Rash and E. A. Grove, manuscript in preparation), which, because of reduced cell proliferation, is almost unidentifiable (Chiang et al., 1996; Ishibashi and McMahon, 2002).

Additional observations demonstrate that, like the roofplate, the cortical hem is functional in Shh mutant mice. The cortical hem provides Wnt3a, a required cell proliferation signal for hippocampal growth (Lee et al., 2000), and is the origin of most Cajal-Retzius (C-R) cells for the hippocampus and neocortex (Bielle et al., 2005; Yoshida et al., 2006). At E10.5, Wnt8b expression marks the hem and hippocampal primordium in wild-type mice (Lee et al., 2000); similar broad bands of Wnt8b expression appear in the Shh mutant telencephalon (Fig. 1I,J, Table 1). At E17.5, presumptive hippocampal field CA3 expresses KA1/Grik 4, which encodes a glutamate receptor subunit, whereas CA1 and neocortical primordium express the POU domain gene, SCIP/ Pou3f1 (Fig. 2A,C) (Tole et al., 1997). In the Shh mutant, complementary expression of KA1/Grik 4 and SCIP/Pou3f1 indicates medial telencephalic differentiation reminiscent of the wild-type hippocampus. Indeed, the distinct, medial domain of KA1/Grik 4 in the mutant strongly suggests a nascent CA3 field (Fig. 2B,D). Further consistent with a functional cortical hem (Yoshida et al., 2006), Reelin-expressing, putative $\mathrm{C}-\mathrm{R}$ cells populate the cortical marginal zone in the Shh mutant ( $n=6$ of 6 ) (Figs. $2 G, H, 3 F, J)$. Thus, substantial development of dorsomedial structures appears in each hemisphere of the Shh mutant mouse.

\section{Cortical primordium develops both dorsally and ventrally in Shh nulls}

Patterns of gene expression characteristic of the cortical ventricular zone, including Emx1, Ngn2, and Pax6, extend ectopically into the ventral telencephalon (Chiang et al., 1996; Rallu et al., 2002) (Fig. $1 \mathrm{~L}$ ). As might be predicted, these altered patterns of 


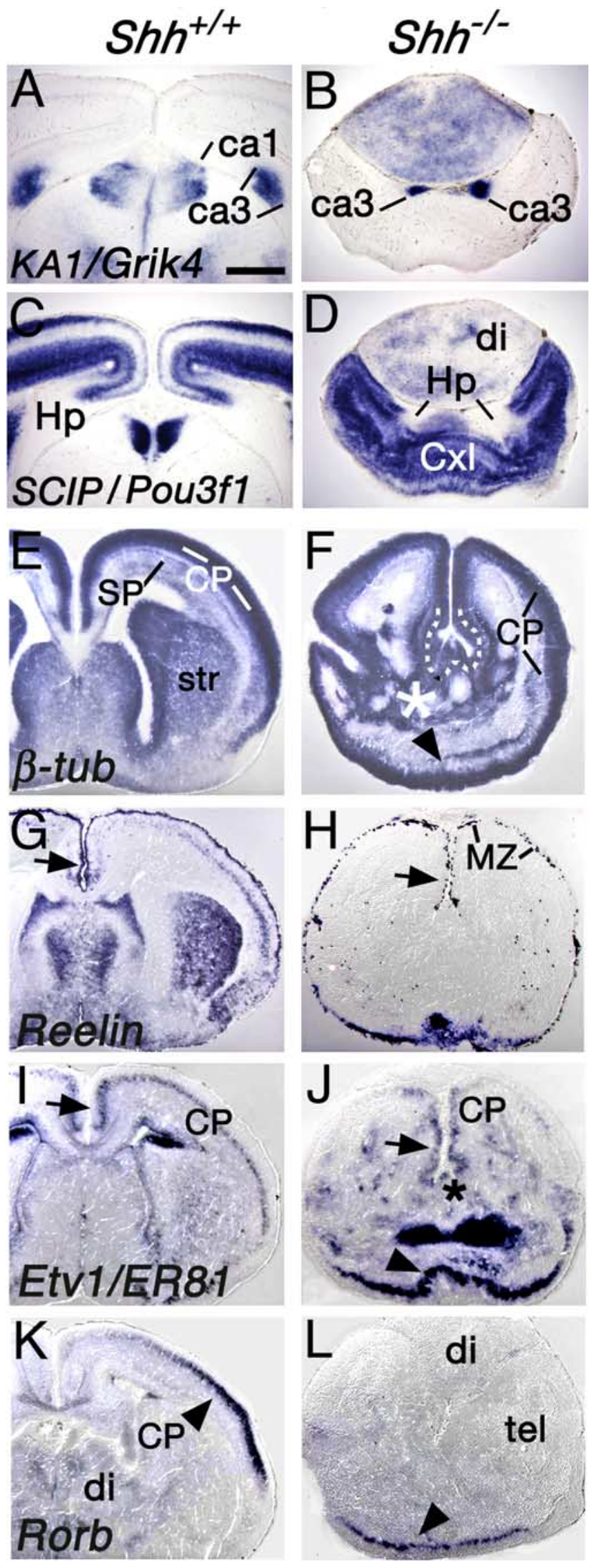

Figure 2. A rudimentary hippocampus and ventral cortical primordium in the Shh mutant. Coronal sections of E17.5 wild-type $(A, C, E, G, I, K)$ and Shh-null $(B, D, F, H, J, L)$ embryos processed for in situ hybridization. $\boldsymbol{A}-\boldsymbol{D}$, The presumptive hippocampal CA3 region is $K A 1 /$ Grik4-

\section{Wildtype}

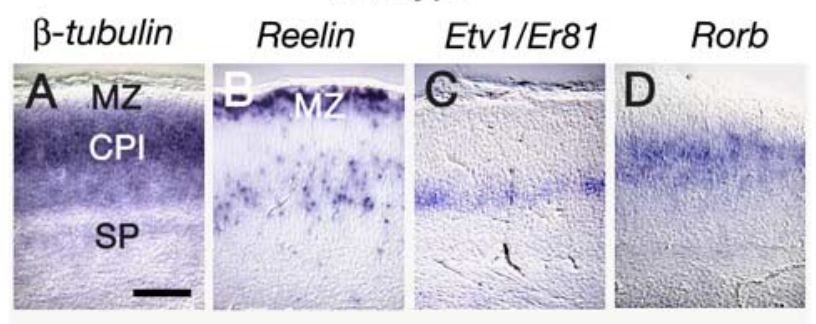

$\mathrm{Shh}^{-1-}$

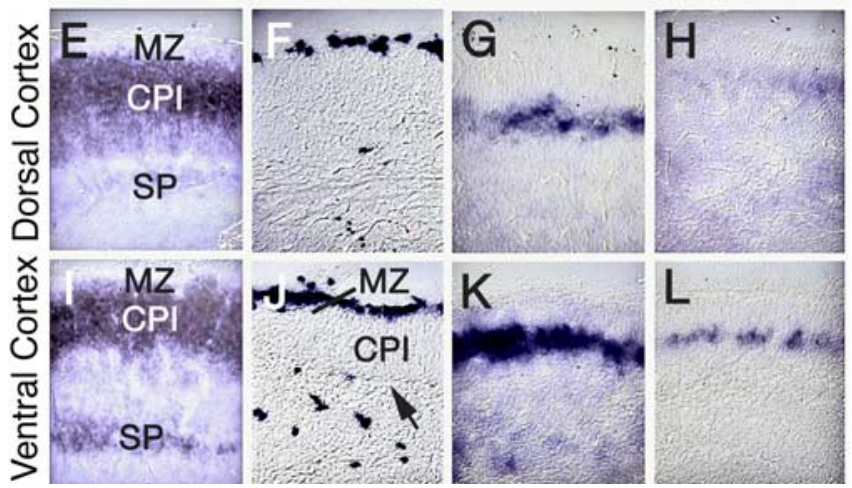

Figure 3. Layering in dorsal and ectopic ventral cortical primordium of Shh mutant mice. $A-D$, High magnification, coronal sections through E17.5 wild-type cortex processed with in situ hybridization to show expression of $\beta$-tubulin $(\boldsymbol{A})$, a pan-neuronal marker, and genes associated with particular cortical layers (see text) $(\boldsymbol{B}-\boldsymbol{D})$. Reelin is expressed in the marginal zone (MZ), the future layer I of neocortex (B). $\boldsymbol{E}-\boldsymbol{L}$, By the same gene expression markers, Shh mutants display a cortical plate, and possibly a subplate in both dorsal and ventral telencephalon $(A, E, I)$. The CP can be seen by morphology in $J$ (arrow indicates lower boundary of the $(P)$. Cells expressing Reelin are sparser in the Shh mutant but mark the $M Z(B, F, J)$. Etv 1 and Rorb are expressed in dorsal $(\boldsymbol{G}, \boldsymbol{H})$ and ventral $(\boldsymbol{K}, \boldsymbol{L})$ cortical primordium in the Shh mutant. The three layer selective markers appear in approximately similar positions in the depth of the $C P$ in wild type and mutant $(\boldsymbol{A}-\boldsymbol{H})$. Scale bar, $100 \mu \mathrm{m}$. Abbreviations: CPI, Cortical plate; MZ, marginal zone; SP, subplate.

gene expression are followed by structural transformations. At E17.5, a cortical plate and marginal zone form a distinct cortical primordium in both control mice and Shh mutants (Figs. $2 E-H$, $3 E, F, I, J)$. However, in the mutants, the cortical primordium reaches far into the ventral telencephalon (Fig. $2 F$, arrowhead).

Bands of gene expression selective to particular neocortical layers (Miyashita-Lin et al., 1999; Rubenstein et al., 1999; Garel et al., 2003; Hevner et al., 2003) also appear in the Shh mutant (Figs. $2 I-L, 3 C, D, G, H, K, L)$. Within the dorsal cortical primordium, and to a lesser extent ventrally, these genes are expressed in a pial to ventricular pattern similar to wild type (Fig. 3C, D, G,H). Dorsalization shifts the regional expression of these genes ventrally,

positive; SCIP/Pou3f1-negative in a wild-type mouse $(A, C)$. The approximate boundaries of CA1 and $C A 3$ are indicated in $\boldsymbol{A}$ (ca1, ca3). Similar complementary expression of $K A 1 / G r i k 4$ and SCIP/Pou3f1 is seen in the medial telencephalon in a Shh ${ }^{-1-}$ embryo (regions marked ca3 and Hp in adjacent sections; $\boldsymbol{B}, \boldsymbol{D})$. $\boldsymbol{E}-\boldsymbol{L}$, The $\beta$-tubulin-expressing, neuron-dense cortical plate reaches across the ventral midline in Shh nulls $(\boldsymbol{F}$, arrowhead) and envelops disorganized deep structures ( $\boldsymbol{F}$, asterisk). Cortical primordium in both control and Shh mutant mice expresses genes that mark postnatal neocortical layer $1(\operatorname{Reelin} ; \boldsymbol{G}, \boldsymbol{H})$, layer $5($ Etv $1 /$ Er $81 ; \boldsymbol{I}, \boldsymbol{J})$, and layer 4 $($ Rorb; $\boldsymbol{K}, \boldsymbol{L})$. Etv1/Er81 and Rorb expression crosses the ventral midline in the Shh mutant $(J, L$, arrowheads). Note the interhemispheric fissure ( $G-J$, arrows), especially well marked by reelin expression $(\boldsymbol{G}, \boldsymbol{H})$. Scale bar: $\boldsymbol{A}, \boldsymbol{C}, 375 \mu \mathrm{m} ; \boldsymbol{E}, \mathbf{G}, \boldsymbol{I}, \boldsymbol{K}, 600 \mu \mathrm{m} ; \boldsymbol{B}, \boldsymbol{D}, \boldsymbol{F}, \boldsymbol{H}, \boldsymbol{J}, \boldsymbol{L}, 200 \mu \mathrm{m}$. Abbreviations: $\mathrm{CP}$, Cortical plate; $\mathrm{CXl}$, cortex-like; di, diencephalon; Hp, hippocampus; MZ, marginal zone; sp, subplate; str, striatum; tel, telencephalon. 


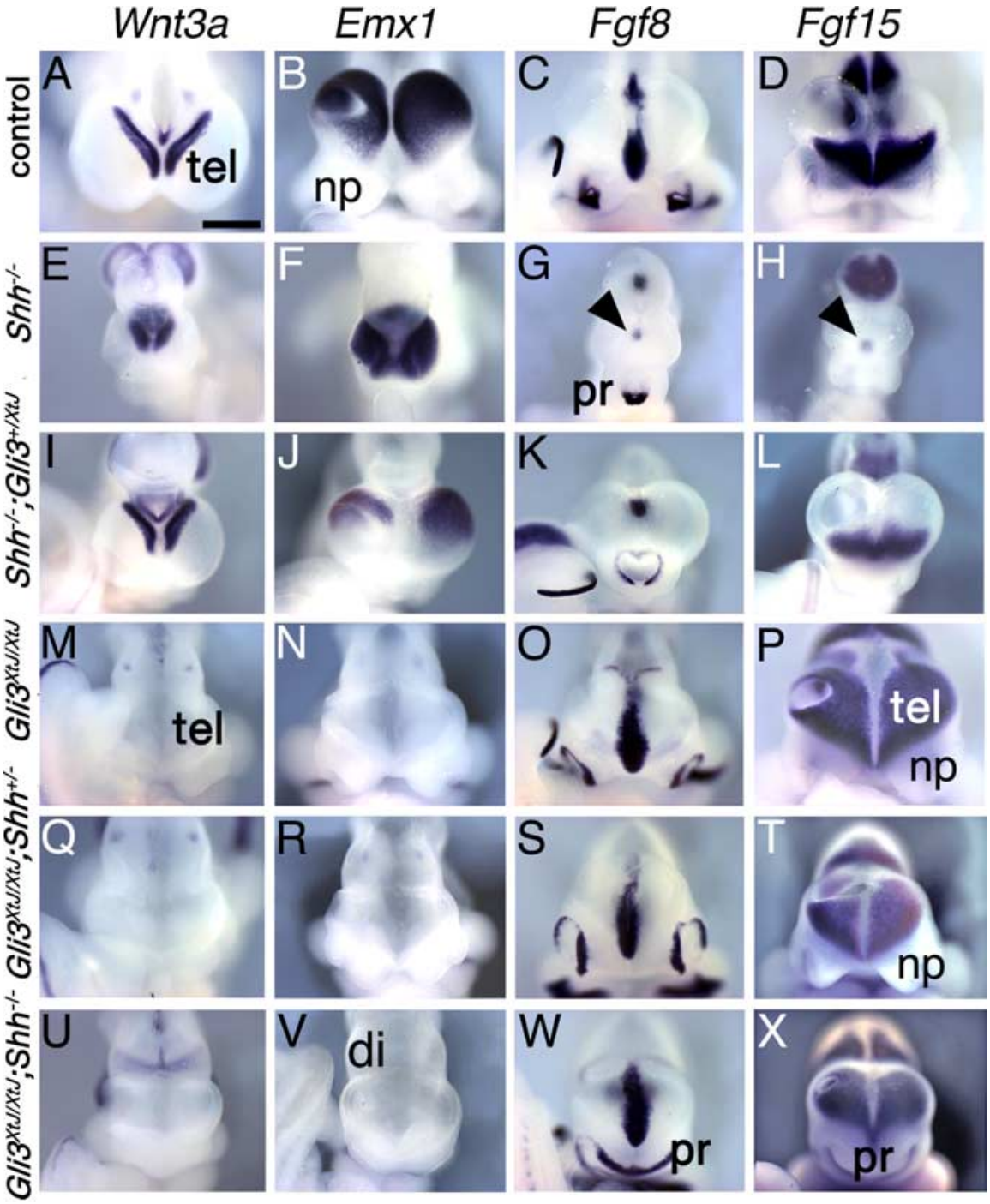

Figure 4. Shh and Gli3 do not show reciprocal effects on dorsal-ventral patterning. Whole-mount in situ hybridization of E10.5 control and $S h h ; X^{\prime} t^{\prime}$ compound mutant embryos. Brains viewed dorsally $(\boldsymbol{A}, \boldsymbol{E}, \boldsymbol{F}, \boldsymbol{I}, \boldsymbol{J}, \boldsymbol{M}, \boldsymbol{Q}, \boldsymbol{U})$ or frontally (all other panels). $\boldsymbol{A}-\boldsymbol{D}$, In control telencephalon, Wnt3a is expressed in the cortical hem, Emx1 in the cortical primordium, Fgf8 rostrally, and Fgf15 ventrally. $\boldsymbol{E}-\boldsymbol{H}$, In Shh mutants, Wnt3a expression marks the cortical hem and Emx 1 is expressed broadly in the telencephalon; Fgf8 and Fgf15 expression is greatly reduced ( $\boldsymbol{G}, \boldsymbol{H}$, arrowheads). Indeed, the spot of $F g f 15$ expression seen in $\boldsymbol{H}$ is in the underlying eye field, not in the telencephalon. $I-L$, Partial rescue of $E m x 1$ and Fgf8/15 expression patterns occurs after removing one

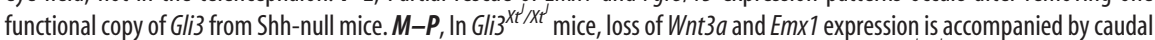
and dorsal overexpression of $F g f 8 / 15$, particularly $F g f 15(\boldsymbol{P})$. These gene expression patterns in $\mathrm{Gli}^{\mathrm{Xt} / \mathrm{Xt}}$ mice are unaffected by loss of one $(\mathbf{Q}-\boldsymbol{T})$ or both $(\boldsymbol{U}-\boldsymbol{X})$ Shh alleles. Scale bar, $600 \mu \mathrm{m}$. Abbreviations: tel, telencephalon; pr, proboscis; np, nasal primordia.

resulting in bands of expression that cross the ventral midline (Figs. $2 J, L, 3 K, L)(n=6$ of 6$)$.

Thus, early dorsal-to-ventral gene expression shifts in the Shh mutant telencephalon reflect a respecification of the ventral telencephalon to a dorsal fate. In consequence, the ventral part of the telencephalon differentiates as layered cortex.

\section{Rostral continuity of the hemispheres and loss of Fgf signaling}

Although the dorsal midline is evident in Shh mutants, the rostral interhemispheric fissure and adjacent septal nuclei do not form. Similar defects occur in mice deficient in telencephalic Fgf signaling (Meyers et al., 1998; Gutin et al., 2006; Storm et al., 2006; Tole et al., 2006); conversely, Fgf8 can induce an ectopic sulcus in the chick telencephalon that resembles the rostral sulcus (Crossley et al., 2001). Strongly suggesting that deficient Fgf signaling contributes to the Shh mutant phenotype, $F g f 8$ gene expression in the mutant telencephalon is weak and transient (Aoto et al., 2002; Ohkubo et al., 2002). The Shh mutant further shows loss or near loss of expression of $F g f 3,15,17$, and 18 (Fig. $4 H$ ) (data not shown). In wild-type mice, $F g f 8,17$, and 18 expression overlaps at the rostral pole of the telencephalon (Heikinheimo et al., 1994; Crossley and Martin, 1995; Bachler and Neubuser, 2001); in a mostly separate domain in the ventral telencephalon, $F g f 3$ and Fgf15 are expressed (Fig. 4C,D; supplemental Fig. 2, available at www. jneurosci.org as supplemental material). Thus, the Shh mutant loses expression of Fof genes, encoding multiple Fgf ligands, in a sizeable rostroventral region of the telencephalon.

\section{Depleting Gli3 restores Fgf gene expression and rostroventral patterning, without fully inhibiting dorsal fate}

Replacing one or both functional Gli3 alleles in Shh or Smo mutants with the extratoes mouse mutant $\left(\mathrm{Xt}^{J}\right)$ allele partially restores Fgf8 expression at multiple sites in the embryo (Aoto et al., 2002; Kuschel et al., 2003), and rostroventral telencephalic expression of $\mathrm{Fgf3}, \mathrm{Fgf15}, \mathrm{Fgf17}$, and $\mathrm{Fgfl} 18$ (Fig. $4 K, L$, Table 2) (data not shown). Upregulated $\mathrm{Fg} f$ gene expression correlates with restoration of the rostral sulcus and septum (Fig. 5D-F).

Although ventral structures, such as the striatum, are substantially rescued in the compound mutant (Litingtung and Chiang, 2000; Rallu et al., 2002), ectopic cortical primordium extends nearly as far ventrally as in mice lacking Shh alone (Fig. $5 D-F)$. What accounts for the misalignment of ventral and dorsal domains? The ability of ectopic Gli3R to induce ectopic intermediate/dorsal cell types in the spinal cord (Meyer and Roelink, 2003) suggests that Gli3R could also induce dorsal structure in the telencephalon. One possibility, therefore, is that levels of Gli3R in the compound mutant telencephalon are insufficient to block ventral structure, but sufficient, in the absence of Shh, for ectopic specification of cortex. This model gives Gli3 an active role in cortical specification. Misalignment is also consistent, however, with the model in which a telencephalic dorsalizing factor is inhibited by Shh and disinhibited by Gli3 (Rallu et al., 2002). In the absence of Shh, reduction of Gli3 has no effect; the dorsalizing factor prevails and ectopic cortex is specified.

In the latter influential model of $\mathrm{D} / \mathrm{V}$ patterning in the telencephalon, $\mathrm{D} / \mathrm{V}$ patterning of the telencephalon requires ventral repression of Gli3 function by Shh, and dorsal repression of Shh signaling by Gli3. In the absence of both Shh and Gli3, other factors specify dorsal and ventral identities unimpeded, resulting 
in a near-normal D/V pattern (Rallu et al., 2002). The specification of ventral cell identities in mice deficient in both Shh and Gli3 has been demonstrated repeatedly (Fuccillo et al., 2006). Here, we test the second part of the model, which predicts that the dorsal telencephalon is also specified near-normally in Gli3/Shh compound mutant mice.

We removed one or both functional copies of $S h h$ from $X t^{J} / X t^{J}$ mutants, and assessed the foremost defects of the $X t^{J} / X t^{J}$ dorsal telencephalon, namely, a defective cortical primordium, reduction of the cortical hem, and dorsal expansion of normally rostroventrally expressed genes (Theil et al., 1999; Tole et al., 2000; Rallu et al., 2002; Kuschel et al., 2003; Theil, 2005). These features, represented by patterns of Emx, Wnt, and Fgf gene expression, are all apparent in $X t^{J} / X t^{J}$ mutant mice by E10.5 (Fig. $4 M-P$ ).

In the $X t^{J} / X t^{J}$ mouse, $W n t 3 a$ and $E m x 1$ expression are lost, and $F g f 8$ and $F g f 15$ expression expands (Fig. $4 M-P$ ). The enormous expansion of $F g f 15$ expression from a ventral domain to virtually the entire telencephalon is a particularly striking example of "ventralization" in the $X t^{J}$ / $X t^{J}$ telencephalon. Moreover, increased dorsal expression of Fgf15 is evident earlier than expanded expression of other genes, such as Dlx2, which is apparent only after E10.5 (supplemental Fig. 3, available at www. jneurosci.org as supplemental material).

Each of the defects described in E10.5 $X t^{J} / X t^{J}$ brains persists when one copy of Shh is removed (Fig. 4Q-T). The $X t^{J} / X t^{J}$; $\mathrm{Shh}^{-1-}$ genotype was rare (four nonexencephalic E10.5 embryos recovered from $>20$ litters), but the sample is consistent: dorsomedial features are lost, and rostroventral features are enhanced. The presence of a proboscis instead of nasal primordia indicates complete loss of Shh in these embryos (Fig. $3 W, X)$ and alters the shape of the rostral forebrain, but the telencephalic phenotype is the same as in $X t^{J} / X t^{J}$ mutants (Fig. $4 U-X$ ). Our findings demonstrate that the dorsal telencephalon remains highly abnormal in Gli3/Shh compound mutant mice: basic D/V pattern is not recovered.

A shared finding in this and a previous study is that the dorsal midline is disrupted in both $X t^{J} / X t^{J}$ and $S h h^{-I-} ; X t^{J} / X t^{J}$ mutants (Rallu et al., 2002; this study), but this is likely attributable to the dominance of the $X t^{J}$ phenotype, rather than the loss of Shh itself. Discrepancies between the two studies are likely to be attributable to the ease with which specific phenotypic features can be identified as present or absent in the small double-null mutant forebrain. We assessed particularly conspicuous features, including expression of Emx1 in the cortical primordium. At E10.5, Emx1 is strongly expressed in wild-type mice, but lost in $X t^{J} / X t^{J}$ mice. We also analyzed expression of $F g f 15$, a normally ventrally expressed gene that shows particularly marked dorsal expansion in the $\mathrm{Xt}^{\mathrm{J}} /$ $X t^{J}$ mutant by E10.5. In contrast, gene expression markers previously used to establish ventralization in the $X t^{J} / X t^{J}$ mutant (Tole et al., 2000; Rallu et al., 2002), such as the expansion of $D l \times 2$ expression into the rostrodorsal telencephalon, are readily apparent at E12.5, but not E10.5 (supplemental Fig. 3, available at www.jneurosci.org as supplemental material), the stage at which striatum; $v C P$, ventral cortical plate.
Table 2. Activities of Gli3 in the doral telencephalon are Shh independent

\begin{tabular}{|c|c|c|c|c|}
\hline & \multicolumn{2}{|l|}{ Medial dorsal } & \multicolumn{2}{|c|}{ Rostral ventral } \\
\hline & Wnt3a; Emx1 & Number & Fgf8; Fgf15 & Number \\
\hline Control embryo expression & + & $38 / 38$ & + & $17 / 17$ \\
\hline $\mathrm{Shh}^{-1-}$ & + & $7 / 7$ & - & $8 / 8$ \\
\hline $\mathrm{Shh}^{-1-} ; G l i 3^{+/ X t^{J}}$ & + & $8 / 8$ & + & $6 / 6$ \\
\hline 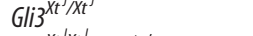 & - & $7 / 7$ & ++ & $8 / 8$ \\
\hline Gli3 $^{X t^{\top} X t^{J}} ; S_{S h}+1-$ & - & $8 / 8$ & ++ & $7 / 7$ \\
\hline $\mathrm{Gli}^{X 3^{\prime} / X t^{\prime}} ; \mathrm{Shh}^{-1-}$ & - & $2 / 2$ & ++ & $2 / 2$ \\
\hline
\end{tabular}

Rostral and ventral identity is partially rescued in the Shh mutant by loss of one functional copy of Gli3. In contrast dorsomedial and rostroventral defects in Gli3 ${ }^{x /} / x^{\top}$ mice are not rescued by loss of one or both copies of Shh.
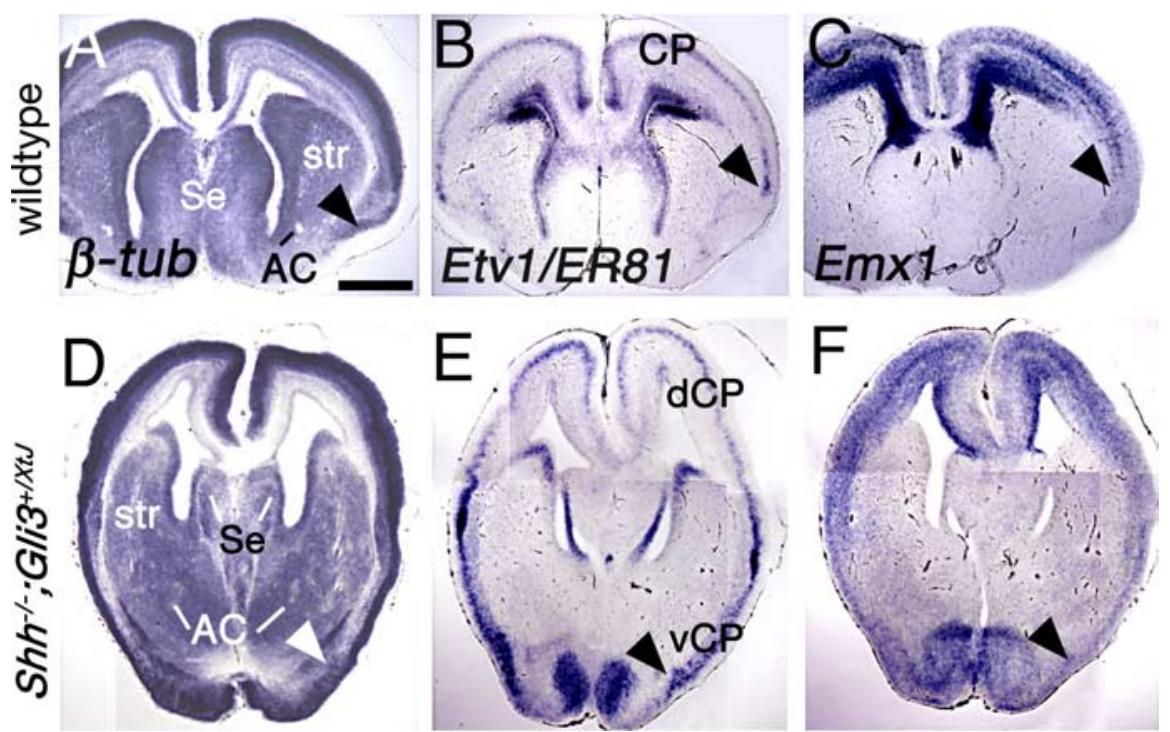

Figure 5. Removing one copy of Gli3 from the Shh mutant partially rescues rostroventral structures, but not ectopic cortical primordium. E17.5 coronal section in situ hybridization. A-C, The wild-type cortical primordium is confined dorsally, marked by a $(\boldsymbol{A}-\boldsymbol{F}$, arrowheads). Scale bar, $600 \mu \mathrm{m}$. Abbreviations: AC, Anterior commissure; dCP, dorsal cortical plate; Se, septum; str,

analysis of double-null mice is practicable (Rallu et al., 2002; this study). Thus, at E10.5, it may not be feasible to distinguish normal from rescued expression of Dlx2 in double nulls. In summary, the persistence of $X t^{J} / X t^{J}$ mutant $\mathrm{D} / \mathrm{V}$ patterning defects in double mutants may have been easier to detect in our study.

\section{Discussion}

Our findings reconcile the functions of Shh and genetic interactions between Shh and Gli3 in the telencephalon and elsewhere in the embryo. In Shh-null mice, the spinal cord develops a dorsal midline; this now appears true for the telencephalon as well (Fig. $6 A)$. Furthermore, major defects in the dorsal telencephalon of Gli3-deficient mice do not reflect the loss of a brake on Shh activity (Fig. 6B,C). The latter finding is consistent with reports that defects attributable to Gli3 deficiency in the spinal cord, limb bud, and at $F g f 8$-expressing sites in $X t^{J} / X t^{J}$ mutants are unaffected by the status of Shh (Aoto et al., 2002; Litingtung et al., 2002; Persson et al., 2002), and supportive of the hypothesis that similar early patterning mechanisms are at work in the limb bud and telencephalon (Ohkubo et al., 2002).

$\mathrm{D} / \mathrm{V}$ patterning of the telencephalon thus requires ventral repression of Gli3 function by Shh signaling (Litingtung and Chiang, 2000; Rallu et al., 2002), but does not require dorsal repression of Shh signaling by Gli3 (this study). Dorsal telence- 
phalic identities are specified incorrectly in the absence of both Shh and Gli3. A remaining role for Shh in the dorsal forebrain, as elsewhere in the neural tube, is to maintain normal levels of cell proliferation and tissue growth (Ishibashi and McMahon, 2002; Ulloa et al., 2007).

These results clear the way for additional investigation of dorsal telencephalic patterning. Shh is dispensable for induction of the $B M P / W n t$-expressing dorsal midline, as, perhaps, is Fgf8, previously suggested to mediate dorsal midline induction by Shh. Expression of multiple $F g f$ genes, including $F g f 8$, is severely reduced in the Shh mutant; moreover, mouse lines engineered for defective Fgf signaling can develop a dorsal telencephalic midline (Garel et al., 2003; Gutin et al., 2006; Storm et al., 2006). Juxtaposed sources of Shh, Fgf8, and BMP/Wnt proteins regulate one another to pattern the telencephalon (Crossley et al., 2001; Ohkubo et al., 2002; Shimogori et al., 2004) but are not the only patterning cues. Given that dorsal epidermis induces roofplate in the spinal cord (Liem et al., 1995) and dorsal gene expression in the chick telencephalon (Gunhaga et al., 2003), dorsal telencephalic midline inductive signals seem likely to derive from adjacent mesenchyme and epidermis.

Initial description of the Shh mutant mouse forebrain as a holosphere suggested the mouse as a model for studying mechanisms underlying human holoprosencephaly (HPE) (Chiang et al., 1996), a developmental disorder in which the cerebral hemispheres separate incompletely or not at all (Muenke and Beachy, 2000; Hayhurst and McConnell, 2003). Approximately 20\% of genetic lesions that have been associated with HPE involve genes encoding components of the Shh signaling pathway (Muenke and Beachy, 2000). We find that the Shh mutant forebrain, although not a holosphere, fits surprisingly well with features of classic human HPE (Takahashi et al., 2003, 2004). Magnetic resonance imaging studies of human infants with HPE show joined septal midline structures in the forebrain, but dorsal separation of the hemispheres. At the diencephalon-telencephalon boundary, additional defects may include obstructed flow of CSF through the forebrain ventricles (Takahashi et al., 2003, 2004). Similarly, in the Shh mutant mouse, the cerebral hemispheres are joined rostrally but separated dorsally, and as development proceeds, ventricular flow is blocked at the level of the third ventricle (B. G. Rash and E. A. Grove, manuscript in preparation). Analysis of primary and secondary effects of loss of Shh on the mouse forebrain may therefore continue to clarify the developmental mechanisms of human HPE.

How the dorsal telencephalon is specified to develop as the intricately organized layered cerebral cortex remains an open question. In the $X t^{J} / X t^{J}$ mouse, anomalies appear in the dorsal telencephalon by E9.5; Gli3 itself is expressed from E8.0 in the dorsal headfold, and in the forebrain anlage from E9.0 (Aoto et al., 2002). Gene expression and morphology indicate that the early progenitor cells of the cortical ventricular zone (VZ) are disorganized, losing their apical/basal cell polarity, and that postmitotic neurons form clusters, rather than layers, beginning with the failure of the earliest born cortical neurons to form a preplate (Theil et al., 1999; Tole et al., 2000; Theil, 2005). Cortical VZ progenitors express transcription factor genes associated with cortical development, such as Ngn2, Pax6, and Emx2, but Emx1 expression, initiated later in the telencephalon than $E m \times 2$, does not upregulate on schedule in the mutant (Simeone et al., 1992; Theil et al., 1999; Tole et al., 2000). In brief, several features of the $X t^{J} / X t^{J}$ telencephalon indicate that, in the absence of Gli3, the earliest differentiation of the cortex, and perhaps its specification, is interrupted.
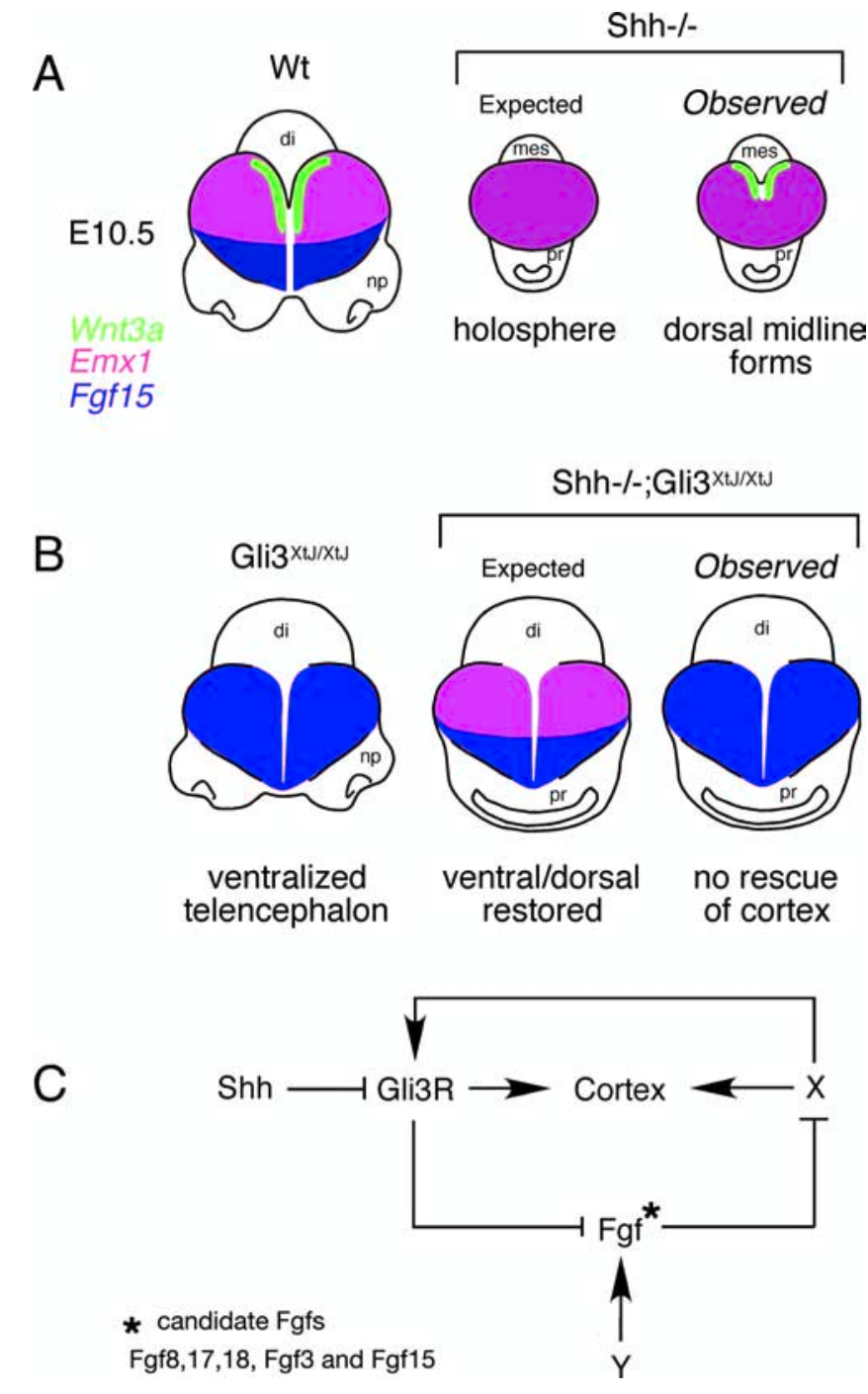

Figure 6. Summary of dorsal telencephalic patterning. Schematics in $\boldsymbol{A}$ and $\boldsymbol{B}$ represent frontal views of the developing brain at E10.5. In wild-type mice, the nasal primordia (np) and diencephalon (di) are adjacent to the telencephalon. Three gene expression patterns were selected to indicate the dorsal (Emx1; purple) and ventral (Fgf15; blue) telencephalon and the cortical hem (Wnt3a; green). $\boldsymbol{A}$, The telencephalon in the Shh-null mouse was expected (see text) to form a holosphere, without midline division. The mutant telencephalon, as observed, divides dorsally into cortical hemispheres with an intervening cortical hem. $\boldsymbol{B}$, In the $X t / X t^{\top}$ mouse, the telencephalon is ventralized. Additional removal of both copies of $S h h$ was expected (see text) to restore the dorsal telencephalon. Instead, no rescue occurs; the telencephalic phenotype of the $X t^{t} / X t^{J}$ appears independent of the status of Shh. $C, X$ represents factors that specify the cerebral cortex and direct its early differentiation. Y represents Shh-independent inducers of $\mathrm{Fg}$ gene expression, revealed by persistent expression of $\mathrm{Fgf8}$ and $\mathrm{Fgf15}$ in double Gli3/Shh mutants (see text). Gli3R is a component of at least one major pathway downstream of $X$. Gli3R may actively induce layered cortex (see text) or promote cortical development indirectly. An instance of the latter is the inhibition of $\mathrm{Fg}$ gene expression by Gli3R. This inhibition protects the dorsal telencephalon from excess Fgf signaling that might otherwise promote ventral, and inhibit dorsal, identities (see text).

Emx2 and Pax6 together have been suggested as "selector" genes for cortical fate (Muzio et al., 2002). In mice lacking both, dorsal tissue forms in the telencephalon but develops as basal ganglia rather than cortex (Muzio et al., 2002). Although both Pax6 and Emx2 are substantially expressed in the $X t^{J} / X t^{I}$ dorsal telencephalon (Theil et al., 1999; Tole et al., 2000; Theil, 2005), they are not sufficient to drive structural formation of the cortex, perhaps because their pattern of expression becomes increasingly 
disorganized, or because Gli3 is responsible for critical steps downstream of Pax6 and Emx2.

Contributing to this disruption may be the excess of Fgf signaling in the $X t^{I} / X t^{I}$ dorsal telencephalon (this study). Fgf signaling promotes ventral and suppresses dorsal identities in the telencephalon (Kuschel et al., 2003; Gutin et al., 2006); for example, beads coated with Fgf8 upregulate Dlx2 and downregulate Emx1 expression in dorsal telencephalic explants (Kuschel et al., 2003). A close correlation has been noted in the $X t^{J} / X t^{J}$ telencephalon between the selectively rostrodorsal overexpression of ventral genes such as $D l \times 2$ and the expanded domain of $F g f 8$ expression, but the latter seems too limited to explain widespread loss of cortical histology and gene expression (Kuschel et al., 2003). We find, however, that expression of other Fgf genes, including Fgf17, and, most prominently, $F g f 15$, are upregulated extensively in the $X t^{J} / X t^{J}$ dorsal telencephalon, with the potential for disrupting cortical development.

Whether Gli3R permits cortical specification or differentiation, or both, by inhibiting Fgf signaling remains to be tested, but fits with correlations among Gli3 gene dosage, levels of telencephalic Fgf gene expression, and the D/V spread of cortical primordium (this study). We propose a provisional model, similar in outline to that described above (Rallu et al., 2002). That is, unidentified factors promote cortical specification in the dorsal telencephalon, are inhibited by Fgf activity, and are disinhibited by Gli3R-mediated inhibition of Fgf gene expression (Fig. 6C).

Note added in proof. While this paper was in press, a paper reporting evidence for a roofplate in the telencephalon of $\mathrm{Shh}^{-1-}$ mouse embryos was published by Fernandes et al. (2007).

\section{References}

Aoto K, Nishimura T, Eto K, Motoyama J (2002) Mouse GLI3 regulates Fgf8 expression and apoptosis in the developing neural tube, face, and limb bud. Dev Biol 251:320-332.

Bachler M, Neubuser A (2001) Expression of members of the Fgf family and their receptors during midfacial development. Mech Dev 100:313-316.

Backman M, Machon O, Mygland L, van den Bout CJ, Zhong W, Taketo MM, Krauss S (2005) Effects of canonical Wnt signaling on dorso-ventral specification of the mouse telencephalon. Dev Biol 279:155-168.

Bielle F, Griveau A, Narboux-Neme N, Vigneau S, Sigrist M, Arber S, Wassef M, Pierani A (2005) Multiple origins of Cajal-Retzius cells at the borders of the developing pallium. Nat Neurosci 8:1002-1012.

Buscher D, Grotewold L, Ruther U (1998) The $\mathrm{Xt}^{\mathrm{J}}$ allele generates a Gli3 fusion transcript. Mamm Genome 9:676-678.

Cheng X, Hsu CM, Currle DS, Hu JS, Barkovich AJ, Monuki ES (2006) Central roles of the roof plate in telencephalic development and holoprosencephaly. J Neurosci 26:7640-7649.

Chiang C, Litingtung Y, Lee E, Young KE, Corden JL, Westphal H, Beachy PA (1996) Cyclopia and defective axial patterning in mice lacking Sonic hedgehog gene function. Nature 383:407-413.

Chizhikov VV, Millen KJ (2005) Roof plate-dependent patterning of the vertebrate dorsal central nervous system. Dev Biol 277:287-295.

Crossley PH, Martin GR (1995) The mouse Fgf 8 gene encodes a family of polypeptides and is expressed in regions that direct outgrowth and patterning in the developing embryo. Development 121:439-451.

Crossley PH, Martinez S, Ohkubo Y, Rubenstein JL (2001) Coordinate expression of Fgf8, Otx2, Bmp4, and Shh in the rostral prosencephalon during development of the telencephalic and optic vesicles. Neuroscience 108:183-206.

Echelard Y, Epstein DJ, St-Jacques B, Shen L, Mohler J, McMahon JA, McMahon AP (1993) Sonic hedgehog, a member of a family of putative signaling molecules, is implicated in the regulation of CNS polarity. Cell 75:1417-1430.

Ericson J, Muhr J, Placzek M, Lints T, Jessell TM, Edlund T (1995) Sonic hedgehog induces the differentiation of ventral forebrain neurons: a common signal for ventral patterning within the neural tube. Cell 81:747-756.

Fernandes M, Gutin G, Alcorn H, McConnell SK, Hébert JM (2007) Muta- tions in the BMP pathway in mice support the existence of two molecular classes of holoprosencephaly. Development 134:3789-3794.

Fuccillo M, Rallu M, McMahon AP, Fishell G (2004) Temporal requirement for hedgehog signaling in ventral telencephalic patterning. Development 131:5031-5040.

Fucillo M, Joyner AL, Fishell G (2006) Morphogen to mitogen: the multiple roles of hedgehog signalling in vertebrate neural development. Nat Rev Neurosci 7:772-783.

Furuta Y, Piston DW, Hogan BL (1997) Bone morphogenetic proteins (BMPs) as regulators of dorsal forebrain development. Development 124:2203-2212.

Garel S, Huffman KJ, Rubenstein JLR (2003) Molecular regionalization of the neocortex is disrupted in Fgf8 hypomorphic mutants. Development 130:1903-1914.

Grove EA, Fukuchi-Shimogori T (2003) Generating the cerebral cortical area map. Annu Rev Neurosci 26:355-380.

Grove EA, Tole S, Limon J, Yip L, Ragsdale CW (1998) The hem of the embryonic cerebral cortex is defined by the expression of multiple Wnt genes and is compromised in Gli3-deficient mice. Development 125:2315-2325.

Gunhaga L, Marklund M, Sjodal M, Hsieh JC, Jessell TM, Edlund T (2003) Specification of dorsal telencephalic character by sequential Wnt and FGF signaling. Nat Neurosci 6:701-707.

Gutin G, Fernandes M, Palazzolo L, Paek H, Yu K, Ornitz DM, McConnell SK, Hebert JM (2006) FGF signalling generates ventral telencephalic cells independently of SHH. Development 133:2937-2946.

Hayhurst M, McConnell SK (2003) Mouse models of holoprosencephaly. Curr Opin Neurol 16:135-141.

Hebert JM, Mishina Y, McConnell SK (2002) BMP signaling is required locally to pattern the dorsal telencephalic midline. Neuron 35:1029-1041.

Hebert JM, Hayhurst M, Marks ME, Kulessa H, Hogan BL, McConnell SK (2003) BMP ligands act redundantly to pattern the dorsal telencephalic midline. Genesis 35:214-219.

Heikinheimo M, Lawshe A, Shackleford GM, Wilson DB, MacArthur CA (1994) Fgf-8 expression in the post-gastrulation mouse suggests roles in the development of the face, limbs and central nervous system. Mech Dev 48:129-138.

Hevner RF, Daza RA, Rubenstein JL, Stunnenberg H, Olavarria JF, Englund C (2003) Beyond laminar fate: toward a molecular classification of cortical projection/pyramidal neurons. Dev Neurosci 25:139-151.

Ishibashi M, McMahon AP (2002) A sonic hedgehog-dependent signaling relay regulates growth of diencephalic and mesencephalic primordia in the early mouse embryo. Development 129:4807-4819.

Kohtz JD, Baker DP, Corte G, Fishell G (1998) Regionalization within the mammalian telencephalon is mediated by changes in responsiveness to Sonic Hedgehog. Development 125:5079-5089.

Kuschel S, Ruther U, Theil T (2003) A disrupted balance between Bmp/Wnt and Fgf signaling underlies the ventralization of the Gli3 mutant telencephalon. Dev Biol 260:484-495.

Lee SM, Tole S, Grove E, McMahon AP (2000) A local Wnt-3a signal is required for development of the mammalian hippocampus. Development 127:457-467.

Liem Jr KF, Tremml G, Roelink H, Jessell TM (1995) Dorsal differentiation of neural plate cells induced by BMP-mediated signals from epidermal ectoderm. Cell 82:969-979.

Liem Jr KF, Tremml G, Jessell TM (1997) A role for the roof plate and its resident TGF $\beta$-related proteins in neuronal patterning in the dorsal spinal cord. Cell 91:127-138.

Litingtung Y, Chiang C (2000) Specification of ventral neuron types is mediated by an antagonistic interaction between Shh and Gli3. Nat Neurosci 3:979-985.

Litingtung Y, Dahn RD, Li Y, Fallon JF, Chiang C (2002) Shh and Gli3 are dispensable for limb skeleton formation but regulate digit number and identity. Nature 418:979-983.

Maynard TM, Jain MD, Balmer CW, LaMantia AS (2002) High-resolution mapping of the Gli3 mutation extra-toes reveals a $51.5-\mathrm{kb}$ deletion. Mamm Genome 13:58-61.

Meyer NP, Roelink H (2003) The amino-terminal region of Gli3 antagonizes the Shh response and acts in dorsoventral fate specification in the developing spinal cord. Dev Biol 257:343-355.

Meyers EN, Lewandoski M, Martin GR (1998) An Fgf8 mutant allelic series 
generated by Cre- and Flp-mediated recombination. Nat Genet 18:136-141.

Miyashita-Lin EM, Hevner R, Wassarman KM, Martinez S, Rubenstein JL (1999) Early neocortical regionalization in the absence of thalamic innervation. Science 285:906-909.

Muenke M, Beachy PA (2000) Genetics of ventral forebrain development and holoprosencephaly. Curr Opin Genet Dev 10:262-269.

Muzio L, DiBenedetto B, Stoykova A, Boncinelli E, Gruss P, Mallamaci A (2002) Conversion of cerebral cortex into basal ganglia in $\operatorname{Emx} 2(-/-)$ Pax6(Sey/Sey) double-mutant mice. Nat Neurosci 5:737-745.

Ohkubo Y, Chiang C, Rubenstein JL (2002) Coordinate regulation and synergistic actions of BMP4, SHH and FGF8 in the rostral prosencephalon regulate morphogenesis of the telencephalic and optic vesicles. Neuroscience 111:1-17.

Persson M, Stamataki D, te Welscher P, Andersson E, Bose J, Ruther U, Ericson J, Briscoe J (2002) Dorsal-ventral patterning of the spinal cord requires Gli3 transcriptional repressor activity. Genes Dev 16:2865-2878.

Rallu M, Machold R, Gaiano N, Corbin JG, McMahon AP, Fishell G (2002) Dorsoventral patterning is established in the telencephalon of mutants lacking both Gli3 and Hedgehog signaling. Development 129:4963-4974.

Roelink H, Porter JA, Chiang C, Tanabe Y, Chang DT, Beachy PA, Jessell TM (1995) Floor plate and motor neuron induction by different concentrations of the amino-terminal cleavage product of sonic hedgehog autoproteolysis. Cell 81:445-455.

Rubenstein JL, Anderson S, Shi L, Miyashita-Lin E, Bulfone A, Hevner R (1999) Genetic control of cortical regionalization and connectivity. Cereb Cortex 9:524-532.

Shimogori T, Banuchi V, Ng HY, Strauss JB, Grove EA (2004) Embryonic signaling centers expressing BMP, WNT and FGF proteins interact to pattern the cerebral cortex. Development 131:5639-5647.

Simeone A, Gulisano M, Acampora D, Stronaiuolo A, Rambaldi M, Boncinelli E (1992) Two vertebrate homeobox genes related to the Drosophila empty spiracles gene are expressed in the embryonic cerebral cortex. EMBO J 11:2541-2550.
Storm EE, Garel S, Borello U, Hebert JM, Martinez S, McConnell SK, Martin GR, Rubenstein JL (2006) Dose-dependent functions of Fgf8 in regulating telencephalic patterning centers. Development 133:1831-1844.

Takahashi T, Kinsman S, Makris N, Grant E, Haselgrove C, McInerney S, Kennedy DN, Fredrickson K, Mori S, Caviness VS (2003) Semilobar holoprosencephaly with midline "seam": a topologic and morphogenetic model based upon MRI analysis. Cereb Cortex 13:1299-1312.

Takahashi TS, Kinsman S, Makris N, Grant E, Haselgrove C, McInerney S, Kennedy DN, Takahashi TA, Fredrickson K, Mori S, Caviness VS (2004) Holoprosencephaly-topologic variations in a liveborn series: a general model based upon MRI analysis. J Neurocytol 33:23-35.

Tao W, Lai E (1992) Telencephalon-restricted expression of BF-1, a new member of the HNF-3/fork head gene family, in the developing rat brain. Neuron 8:957-966.

Theil T (2005) Gli3 is required for the specification and differentiation of preplate neurons. Dev Biol 286:559-571.

Theil T, Alvarez-Bolado G, Walter A, Rüther U (1999) Gli3 is required for Emx gene expression during dorsal telencephalon development. Development 126:3561-3571.

Tole S, Christian C, Grove EA (1997) Early specification and autonomous development of cortical fields in the mouse hippocampus. Development 124:4959-4970.

Tole S, Ragsdale CW, Grove EA (2000) Dorsoventral patterning of the telencephalon is disrupted in the mouse mutant extra-toesJ. Dev Biol 217:254-265.

Tole S, Gutin G, Bhatnagar L, Remedios R, Hebert JM (2006) Development of midline cell types and commissural axon tracts requires Fgfrl in the cerebrum. Dev Biol 289:141-151.

Ulloa F, Itasaki N, Briscoe J (2007) Inhibitory Gli3 activity negatively regulates Wnt/beta-catenin signaling. Curr Biol 17:545-550.

Wilson SW, Rubenstein JL (2000) Induction and dorsoventral patterning of the telencephalon. Neuron 28:641-651.

Yoshida M, Assimacopoulos S, Jones KR, Grove EA (2006) Massive loss of Cajal-Retzius cells does not disrupt neocortical layer order. Development 133:537-545. 